Canadian Journal of Applied Linguistics

Revue canadienne de linguistique appliquée

\title{
So How Do English Language Learners Use "So"?
}

\section{Jessica Lim}

Volume 21, Number 1, 2018

URI: https://id.erudit.org/iderudit/1051286ar

DOI: https://doi.org/10.7202/1051286ar

See table of contents

Publisher(s)

University of New Brunswick

ISSN

1920-1818 (digital)

Explore this journal

Cite this article

Lim, J. (2018). So How Do English Language Learners Use "So"? Canadian Journal of Applied Linguistics / Revue canadienne de linguistique appliquée, 21(1), 94-122. https://doi.org/10.7202/1051286ar

\section{Article abstract}

The present article compares the use of the discourse marker so between English-dominant speakers and English language learners through an analysis of 20 one-on-one audio-recorded sessions with 10 English-dominant speakers and 10 English language learners. While employment of the discourse marker by both speaker groups was found to be discrepant, one prominent difference was discovered in the English language learner data. Move so, one of so's six discursive functions, was produced with a higher frequency by the English language learners. The findings of the study indicate that while the learner group demonstrated a limited range of functions, as did English language learners in prior studies, they also had an overall lower rate of frequency compared to the English-dominant speakers.
This document is protected by copyright law. Use of the services of Erudit (including reproduction) is subject to its terms and conditions, which can be viewed online.

https://apropos.erudit.org/en/users/policy-on-use/ 


\title{
So How Do English Language Learners Use So?
}

\author{
Jessica Lim \\ University of Toronto
}

\begin{abstract}
The present article compares the use of the discourse marker so between English-dominant speakers and English language learners through an analysis of 20 one-on-one audio-recorded sessions with 10 English-dominant speakers and 10 English language learners. While employment of the discourse marker by both speaker groups was found to be discrepant, one prominent difference was discovered in the English language learner data. Move so, one of so's six discursive functions, was produced with a higher frequency by the English language learners. The findings of the study indicate that while the learner group demonstrated a limited range of functions, as did English language learners in prior studies, they also had an overall lower rate of frequency compared to the English-dominant speakers.
\end{abstract}

\section{Résumé}

Cette étude compare l'emploi du marqueur discursif anglais so entre les personnes de langue maternelle anglaise et les apprenants de l'anglais par le biais d'une analyse de 20 séances enregistrées en tête-à-tête avec 10 personnes de langue maternelle anglaise et 10 apprenants de l'anglais. Les résultats démontrent que l'emploi du marqueur discursif par les deux groupes divergent. La différence la plus notable a été découverte dans les données des apprenants de l'anglais. « Move so », une des six fonctions discursives de so, a été employé plus fréquemment par les apprenants de l'anglais. Les conclusions de cette étude confirment les résultats des études précédentes quant à l'emploi d'un éventail limité de fonctions par les apprenants de l'anglais. De plus, ces participants ont employé le marqueur moins fréquemment que les locuteurs natifs. 


\section{So How Do English Language Learners Use So?}

\section{Introduction}

Despite the growing research on English discourse markers (DMs) in recent years, there is a lack of research on the use of DMs by English language learners (ELLs). The purpose of the present study was to determine if ELLs are capable of employing the DM, $s o$, to convey their own communicative intentions by examining how their use of $s o$ 's different discursive functions compares to that of English-dominant speakers' (EDSs). It is not enough to simply convey words; language learners also need to "convey how those words should be interpreted" (Fox Tree, 2010, p. 270).

Before going any further, some terminology must be explained. I employ the term dominant language to refer to what is commonly described as one's "first language" ("L1"), "mother tongue," or "native language" in other studies. While all of these descriptors refer to the same idea, dominant language is a much clearer and more accurate term, as one's strongest language may not necessarily be one's mother tongue or first/native language. A similar idea applies to language learners. The term "English as a second language" is also a flawed label as a learner of English might already speak two or three other languages, making English their third or fourth language. I refer to the participants in this study as ELLs or EDSs. Throughout the paper, however, other terms are used to identify language learners or dominant speakers of a language if a different label was employed in a separate study and should henceforth be understood as being the cited author's terms. Moreover, I use L1 (one's first language) and L2 (one's second language) in later sections for simplicity and readability in comparing the results with previous studies.

Broadly speaking, DMs are linguistic elements that signal a procedural message, or a core pragmatic sense that is defined as "a meaning separate from any content meaning of the homophonous form" (Fraser, 1990, p. 395). There are three essential conditions for a linguistic element to be considered a DM: connectivity, optionality, and non-truthconditionality (Schourup, 1999). They relate linguistic segments for coherence (Fraser 1999; Lenk, 1998; Schiffrin, 1987; Schourup, 1999) and connect the propositional content of the foregoing and following utterances (Blakemore, 1987). They are also syntactically optional because the absence of one does not influence the grammaticality of the utterance in which it appeared (Brinton, 1996; Schourup, 1999). In other words, the relationship normally signaled by the DM is no longer explicit and may be obscured. Finally, DMs are different from content words, such as girl, because they do not influence the truthconditions of the propositional content. Weak clause association, initiality, orality, and multicategoriality may also be considered as characteristics of DMs, but they are not mandatory attributes.

So is an other-attentive ${ }^{1}$ marker (Bolden, 2009, p. 988) that has been found to be multifunctional. It marks the main topic of discourse by signaling the beginning of a new topic, or returning to the main topic after straying from it (Matzen, 2004); indicates a summary; introduces a confirmation or a request for unknown information; operates as a turn-transition device functioning at the global level of discourse (Schiffrin, 1987); and communicates an inferential relationship (Blakemore, 1988) or a consequence (Van Dijk, 1979) between two propositions. The distinction between non-discursive so as a conjunction and discursive so marking result is that the former functions at the local level 
of discourse, where "only one event is being causally related" (Schiffrin, 1987, p. 203) to the proposition following so. When acting as a DM, so connects multiple events to the cause or result "over a wide range of talk" (Schiffrin, 1987, p. 203). The discursive standalone so (Local \& Walker, 2005; Raymond, 2004), in contrast, manages "the multiple, overlapping units of organization that any turn at talk participates in simultaneously" (Raymond, 2004, p. 210). It was also found to return to or reopen an action that "[had] been on the interactional agenda" (Bolden, 2009, p. 996), or one that had been put on hold and had not yet been closed. Such a function could be used when returning to the main topic after addressing an aside in the same conversation or from a past interaction.

While there is a lack of research in DM use by ELLs, and while it is not reasonable to make any overarching conclusions about DMs or one specific DM based on these studies, they have suggested similar results. The findings have indicated that ELLs have a different rate of frequency, greater variation among the learner group, and a limited range of functions in DM use in comparison to EDSs. Bu (2013) examined the acquisition of DMs such as like and well, among others, by Chinese ELLs, and concluded that there was variation in frequency, gender, and style among the ELLs, and that their use of the DMs' functions was limited compared to that of native speakers. Similarly, Liao (2008) inferred that the learners in that study had only obtained partial acquisition of the DMs' functions and that context was a good indicator of which DM would be used in the talk. Fuller (2003), however, found that ELLs used similar functions of DMs when compared to their native counterparts, but the DMs occurred less frequently and there was greater variation in their use within the learner group. Furthermore, Fuller (2003) attributed the similarity in ELLs' and EDSs' use of oh and well to context. Zarei (2012) also found that oh and well were the most frequently used DMs. Müller (2005) compared German ELLs' use of DMs such as so, well, you know, and like to that of native speakers and discovered that some functions were only used by one of the speaker groups. For example, the German participants signaled result, summarized, and reworded less frequently than the native speakers. In addition, Fung and Carter (2007) and Asik and Cephe (2013) concluded that their respective ELL participants used fewer types of DMs, and with a lower frequency.

Other studies have made valuable contributions toward better understanding how to close the gap between ELLs' and EDSs' use of DMs. Hellermann and Vergun's (2007) analysis of DM use by ELLs concluded that higher proficiency and greater contact with authentic spoken English was associated with greater DM use. Buysse (2014) found that non-prefatory $s O^{2}$ occurred much more frequently in the learner data and concluded that the difference between the native English-speaking group and the learner group was statistically significant. Buysse (2014) attributed this difference to the learners' desire to sound coherent, but having an insufficient DM repertoire, and so's similarity to their corresponding mother tongue (Dutch) DM. On the contrary, Iglesias Moreno (2001), who compared the development of involvement markers and operative markers between ELLs and EDSs, concluded that the learners did not use DMs as frequently as the EDSs did. The author also found that ELLs prefered or demonstrated knowledge of only certain functions of a DM. While Aijmer's (2011) learners used well for speech management, such as when they needed more time to plan their talk, it was not often used to express attitudes or emotions.

When ELLs are not fully aware of all the possible roles of a DM, they may also be unable to understand the intentions of the interlocutors who do employ them. This paper ${ }^{3}$ 
attempts to provide a glance at discursive so and its use by Korean and Japanese ELLs and EDSs in order to determine the comparability of a commonly produced English DM between language learners and EDSs.

\section{Methodology}

\section{Spectrum of So's Functional Categories}

I propose a spectrum (Figure 1) that outlines so's discursive functions - referred to as functional categories in Figure 1-in spoken discourse. The spectrum also depicts the relationship between each functional category and the three underlying functions of so: Marking Main Topic, Connective, and Resultative. All of so's discursive functions presented in this paper embody all three underlying functions to some degree, but they each have a principal role in discourse. The stronger the relevance between the underlying function and the functional category, the darker the shade of gray is on the spectrum. A functional category's primary underlying roles are indicated by the darkest shade of gray.

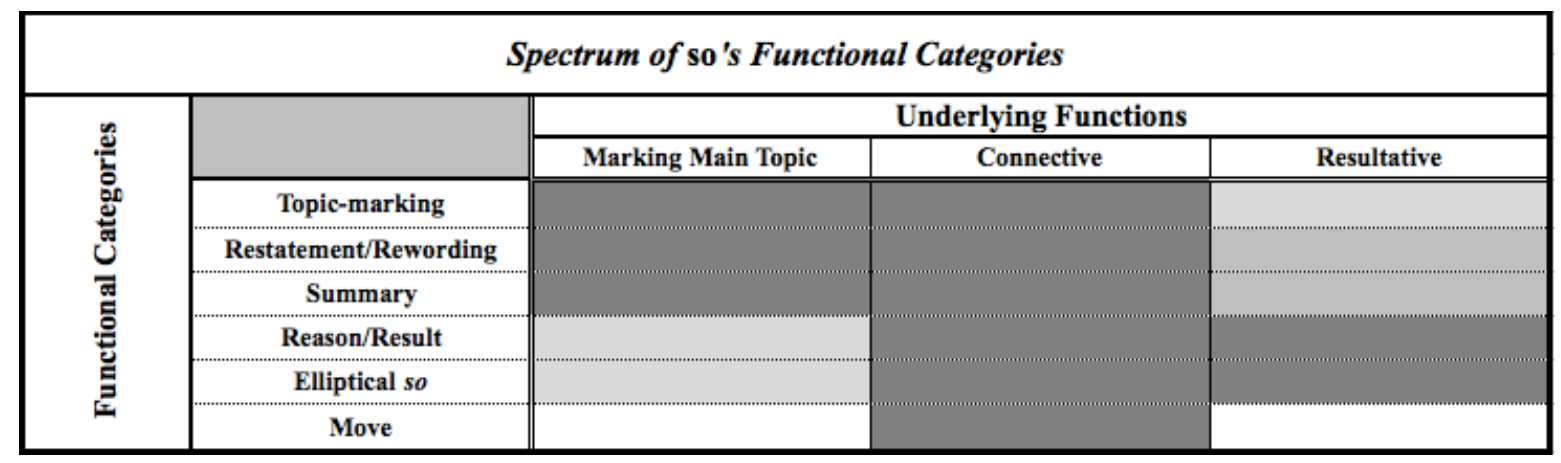

Figure 1. Spectrum of so's functional categories.

Topic-marking so, Restatement/Rewording so, and Summary so exhibit a stronger relationship with marking the main topic than expressing result. Moreover, while employing Reason/Result or Elliptical so may not necessarily lead to a reason or result that puts an end to the talk, their use strongly triggers some sort of conclusion, compared to the other four categories. Unlike the others, Marking Main Topic and Resultative for Move so have been left white to represent ambiguity. According to some scholars, so's core meaning is resultative or connective (Blakemore, 1988; Schiffrin, 1987; Van Dijk, 1979), while others emphasize so's main topic-marking function (e.g., Matzen, 2004). As there is no consensus on the DM's core function, all three "core" categories have been chosen to represent its underlying functions. Furthermore, it is not unusual for frequently employed DMs, such as $s o$, to be assigned general functions, especially since DMs occur "in an extremely wide range of discourse environments" (Schourup, 1999, p. 251). In the present study, discursive so demonstrated its multifunctional nature and all functional categories marked result, connection, and main topic to varying degrees. So's connective function is represented by all of the functional categories (as indicated by the consistent shading throughout the categories), for one of the conditions of a DM is connecting discourse (Schourup, 1999). Sans its connective feature, so's status as a DM would be challenged. 
Table 1 outlines the individual functions of so. In the present paper, so was found to have six discursive functions and two non-discursive functions. During analysis, instances of so were coded into one of these eight functions. However, as the goal of the study was to compare the use of discursive $s o$, productions of the two non-discursive functions, conjunctive and adverbial so, were omitted from analysis, and only the six discursive functions presented in Table 1 were examined. The following is a preview of some of the examples of the six discursive functions that were found in the data.

Table 1

Functions of So

\begin{tabular}{cc}
\hline Discursive functions & Non-discursive functions \\
\hline Topic marking & Adverbial \\
Restatement/Rewording & Conjunctive \\
Summary & \\
Reason/Result & \\
Elliptical so & \\
Move & \\
\hline
\end{tabular}

Topic-marking so

(1) Phil: all right (.) so it starts out with Mr. Bean trying to uh (..) get some= $=$ stuff into his suitcase

Restatement/Rewording so

(1) Liv: I was in the like the red corral that's the first corral so I was in the first heat

Summary so

(1) Liv: $\quad$ so he takes (.) a real-life situation and is able to twist it into a= $=$ way that makes it $($.$) comical$

Reason/Result so

(1) Linus: so they need human candidates who are willing to leave everything= =behind

Elliptical so

(1) Leo: and then (.) he's (.) going on vacation somewhere in England I= $=$ assume? I have no idea or maybe Europe who knows but then he's= $=$ on a train now so.

Move so

(1) Nori: we enjoy talking with each other so and comedians will so pick up= $=$ the so personality like so funny talk or like so many so but the $()=$. $=$ like (.) Mr. Bean will so attend the like so funny action so

These functional categories are defined and examined in further detail in the results section. 


\section{Data Collection and Analysis}

Data were collected from 20 one-on-one sessions between me, the interviewer, and the participants (10 EDSs, five Korean ELLs, and five Japanese ELLs). At the time of data collection, the EDSs attended or were attending English-speaking Canadian universities and had completed most of their schooling in English-speaking North American schools, while the ELLs were foreign adult students who were recruited from one English-language school in Toronto and were enrolled in the high-intermediate or advanced levels at the school.

Although a session was composed of three parts - a semi-monologue, a question/answer interview, and a language background and DM interview - only the semimonologue and question/answer interview are explored in this paper. For the semimonologue, participants were asked to watch Act 3 of "Mr. Bean Rides Again" from the television series, $M r$. Bean, and immediately recount the scene in as much detail as possible. In this scene, Mr. Bean is trying to pack his belongings into a small suitcase for a trip. In order for him to fit everything he wants to bring, he makes some comical sacrifices. After finally managing to squeeze everything into his small suitcase, he finds a larger suitcase that is big enough to fit all of his belongings. Instead of repacking, he simply places the small suitcase that he already packed into the larger one. A video with essentially no dialogue was chosen so that participants would not be influenced by a script when describing the segment. ${ }^{4}$ In the second portion of the session, participants were asked to discuss the plot of a favourite television show, movie, or book and explain their reasoning, describe a character from either the same or a different work, and were asked about their experiences abroad.

A portion of each session was analyzed for consistency. Extracting an equal number of minutes from the beginning of each interview question was impractical, as sometimes the participant had already responded to one interview question along with, or as part of, another question, or the duration of participants' responses was too short. Nevertheless, the following times were extracted from the responses for each participant: the first 2 minutes of the semi-monologue, the first 2 minutes of the favorite television show/movie/book, the first 2 minutes of the reasoning for the choice, the first 2 minutes of the character description, and the first 5 minutes of the experience with culture shock. The aforementioned times were extracted to ensure the consistency of the conversation topics and to present an equal opportunity for DM production. Moreover, after each given limit, the prearranged topics generally veered off into various themes, which could result in a more (or less) frequent production of the DM so. More minutes were extracted from the question about culture shock as the inevitable digressions were postponed. It should also be noted that while an attempt was made to ask the same questions, they were often adjusted midway to meet different participant needs. For instance, if a participant was having trouble responding, it was necessary to alter the question.

Data collection took place at an educational institution in Toronto. Audio recordings were transcribed and the aforementioned portions were analyzed for the occurrence of $s o$. Although participants were aware that they were being audio-recorded, the focus of this study, the DM so, was not revealed until the DM interview. While the instances of so were coded according to its eight functions, only its six discursive functions were analyzed. 
Average rates of use of so were calculated per 100 words for each discursive function, speaker, and speaker group for comparison. Subsequently, independent-samples $t$ tests were conducted using SPSS to determine statistical significance between the EDS and ELL speaker groups, as well as the Korean ELL and Japanese ELL groups. Moreover, instances where the function of $s o$ was unclear or could not be placed under one functional category were removed from analysis.

A small portion (15\%) of the data was originally coded by a colleague in a related field, who was given detailed instructions and relevant training, to measure intercoder reliability. The colleague coded enough of the data to classify instances of the DM into so's eight discursive and non-discursive functions. Any discrepancies were resolved and both coders reached a unanimous agreement. Upon completion of the original project, I recorded all of the data according to slightly altered categories. Instead of the original eight discursive functions, data were coded according to six discursive functions. Two weeks later, I coded the modified categories again, ${ }^{5}$ which was enough time for me to not be able to recall the earlier recoding process and reached a recoding reliability of $95 \%$.

\section{Results}

A total of 289 instances of discursive so (128 occurrences by ELLs and 161 occurrences by EDSs) were analyzed. The left-hand sides of each speaker group column of Table 2 depict the raw scores or the number of instances in which so was used by the EDS group and ELL group, while the right-hand sides show the average rates of frequency. Similarly, the left-hand sides of each ELL speaker group column of Table 3 illustrate the raw scores and the right-hand sides the average rates of frequency of so.

Table 2

Discourse Marker So Raw Scores, Average Rates of Frequency (per 100 Words), and $\mathrm{p}$ Values for Each Discursive Function and Speaker Group

\begin{tabular}{|c|c|c|c|c|c|}
\hline \multirow[b]{2}{*}{ Functions of $s o$} & \multicolumn{2}{|l|}{ EDS } & \multicolumn{2}{|l|}{ ELL } & \multirow[b]{2}{*}{$p$ value } \\
\hline & $\begin{array}{l}\text { Raw } \\
\text { Score }\end{array}$ & Avg. Score & $\begin{array}{l}\text { Raw } \\
\text { Score }\end{array}$ & Avg. Score & \\
\hline Topic-marking & 85 & 0.5394 & 35 & 0.3924 & .35 \\
\hline Reword/Restatement & 5 & 0.0325 & 1 & 0.0149 & .47 \\
\hline Summary & 3 & 0.0185 & 1 & 0.0133 & .76 \\
\hline Reason/Result & 38 & 0.2831 & 11 & 0.1174 & .14 \\
\hline Elliptical & 27 & 0.1908 & 7 & 0.0833 & .32 \\
\hline Move & 3 & 0.0165 & 73 & 0.7844 & .10 \\
\hline Total & 161 & & 128 & & \\
\hline
\end{tabular}

Note. EDS = English-dominant speaker; ELL = English language learner. 
Table 3

Discourse Marker So Raw Scores, Average Rates of Frequency (per 100 Words), and $\mathrm{p}$ Values for Each Discursive Function and English Language Learner (ELL) Group

\begin{tabular}{llllll}
\hline & \multicolumn{2}{l}{ Korean ELL } & \multicolumn{3}{l}{ Japanese ELL } \\
\cline { 2 - 5 } & Raw & & Raw & \\
Functions of so & Score & Avg. Score & Score & Avg. Score & $p$ value \\
\hline Topic-marking & 11 & 0.282 & 24 & 0.5027 & .45 \\
Reword/Restatement & 0 & 0 & 1 & 0.03 & .37 \\
Summary & 1 & 0.0266 & 0 & 0 & .37 \\
Reason/Result & 1 & 0.0262 & 10 & 0.2086 & .15 \\
Elliptical & 4 & 0.096 & 3 & 0.0707 & .53 \\
Move & 7 & 0.1755 & 66 & 1.3933 & .19 \\
\hline Total & 24 & & 104 & & \\
\hline
\end{tabular}

Based on these raw scores, Topic-marking so was the most frequently produced function by the EDSs with 85 instances. They had an average rate of 0.5394 per 100 words. For the ELLs, it was the second-most frequently occurring function (0.3924). Although nearly every participant used so to mark the main topic (only three ELLs did not employ this function), there was no significant difference between the two speaker groups $(p=.35)$. Within the ELL group, the Japanese ELLs (at an average rate of 0.5027 per 100 words) employed the function much more frequently than the Korean ELLs did (at an average rate of 0.282).

Summary so and Move so were the least frequently produced functions by EDSs with only three instances each. For both functions, the three instances were produced by three different EDSs, demonstrating that perhaps the environment in which the interview was conducted may not have provided sufficient opportunity for participants to employ certain functions. Hence, it is not surprising that there were very few instances of Summary so in the ELL data as well. While both Summary so and Restatement/Rewording so were infrequent in the present data, the former occurred less frequently overall than the latter with only one Korean ELL (at an average rate of 0.0133 per 100 words) and three EDSs (at an average rate of 0.0185 ) using Summary so. In comparison, only one Japanese ELL (at an average rate of 0.0149 per 100 words) produced Reword/Restatement so, while the three EDSs employed the function at an average rate of 0.0325 per 100 words. As expected, neither of the two functions demonstrated any significant differences between EDSs and ELLs nor between the two ELL speaker groups.

Moreover, despite only four ELLs (at an average rate of 0.1174 per 100 words) employing Reason/Result so when almost all of the EDSs (at an average rate of 0.2831) produced it at least once, there were no major differences in the manner in which it was employed, and statistical significance was not achieved $(p=.14)$. Within the ELL speaker group, its use was comparable, where the Korean ELLs produced it at a rate of 0.0262 per 100 words and where the Japanese ELLs produced it at a rate of 0.2086 per 100 words; statistical significance was not achieved $(p=.15)$.

The comparison of Elliptical so also did not yield any significant differences $(p=.32)$ between EDSs and ELLs or between the Korean ELLs and Japanese ELLs $(p=.53)$. As with Reason/Result so, the ELLs had a much lower rate of frequency than the 
EDSs, which is possible indication that the language learners have not yet acquired the full capacity to employ all of a DM's functions.

Move $s o$, on the other hand, was the most frequently produced function by the ELLs. More than half of ELLs' so productions (73 of 128 total DM productions by ELLs) marked hesitation and/or were used to hold the floor (Corley \& Stewart, 2008; Kjellmer, 2003). The ELLs produced Move so at an average rate of 0.7844 per 100 words, while the EDSs produced the DM at an average rate of 0.0165 (3 of 161 total DM productions by EDSs). Despite the high rate of frequency of this function by the ELL group in comparison to the EDS group, statistical significance was not achieved between the two speaker groups. Moreover, while this discrepancy was mostly a result of two Japanese ELLs who made up 63 of the 73 instances by ELLs (the average rate of use was 1.3933 for the Japanese ELLs, whereas it was only 0.1755 for the Korean ELLs), statistical significance was not achieved between the two ELL groups $(p=.19)$ either.

While no single participant employed all of so's functions, as shown in Table 4, the greatest range that was used was five out of six functions by three EDSs, where those five functions were different for each speaker.

Table 4

Average Rates of Frequency for Discursive So

\begin{tabular}{|c|c|c|c|c|c|c|c|}
\hline \multirow[t]{2}{*}{ Speaker group } & \multirow[t]{2}{*}{ Participant } & \multicolumn{5}{|c|}{ Discursive functions } & \multirow[b]{2}{*}{ Result } \\
\hline & & Topic-marking & Elliptical & Move & Summary & Restatement & \\
\hline \multirow{10}{*}{ Ells } & Seojun & 0 & 0 & 0.246 & 0 & 0 & 0 \\
\hline & Nara & 0 & 0.1058 & 0.1058 & 0 & 0 & 0 \\
\hline & Kaho & 0 & 0.1486 & 0.2972 & 0 & 0.1486 & 0 \\
\hline & Kota & 0.0966 & 0 & 0 & 0 & 0 & 0.2899 \\
\hline & Hana & 0.2205 & 0.1103 & 0 & 0 & 0 & 0 \\
\hline & Tatsuki & 0.3195 & 0.1065 & 0.1065 & 0 & 0 & 0 \\
\hline & Lina & 0.3927 & 0.1309 & 0.3927 & 0 & 0 & 0.1309 \\
\hline & Kyuri & 0.7968 & 0.1328 & 0.1328 & 0.1328 & 0 & 0 \\
\hline & Nori & 0.9852 & 0.0985 & 3.4483 & 0 & 0 & 0.197 \\
\hline & Taro & 1.1123 & 0 & 3.1146 & 0 & 0 & 0.5562 \\
\hline \multirow{10}{*}{ EDSs } & Linus & 0.2584 & 0 & 0 & 0 & 0 & 0.3876 \\
\hline & May & 0.2956 & 0.1478 & 0 & 0 & 0.0739 & 0.2956 \\
\hline & Troy & 0.4016 & 0.0669 & 0 & 0 & 0 & 0.0669 \\
\hline & Phil & 0.4932 & 0 & 0 & 0 & 0 & 0.9864 \\
\hline & Jodi & 0.4983 & 0.0554 & 0 & 0 & 0 & 0 \\
\hline & Liv & 0.5184 & 0.1728 & 0 & 0.0576 & 0.1728 & 0.1152 \\
\hline & Ella & 0.6281 & 0.2791 & 0.0698 & 0 & 0 & 0.2094 \\
\hline & Lara & 0.641 & 0.0493 & 0.0493 & 0.0493 & 0 & 0.4438 \\
\hline & Leo & 0.6467 & 0.0462 & 0.0462 & 0 & 0 & 0.0924 \\
\hline & Neil & 1.0125 & 1.0903 & 0 & 0.0779 & 0.0779 & 0.2336 \\
\hline
\end{tabular}

Table 4 depicts the average rates of frequency for each participant, and the rates marked as 0 indicate that the individual did not use the function at all. The table is organized from the lowest rate of frequency for the most frequently used function, Topicmarking so, to the highest rate of that function for each speaker group separately. Overall, the range was greater for EDSs as most of them employed four to five functions, while most of the ELLs used two to three functions.

The relatively large differences between the EDSs and ELLs (see Table 2), indicate that the latter group has not yet acquired the ability to employ so's distinct discursive 
functions. Despite the low average rates of frequency for functions such as Summary and Reword/Restatement, the greater difference in the speakers' use of Elliptical, Topicmarking, and Reason/Result so supports that the ELLs do not have sufficient knowledge in employing discursive so. The ELL group's understanding of discursive so is further questioned when their frequent use of Move so is as striking as it is. Move so had the greatest difference in average rate of frequency (0.7679) among all of the functions. It is also worth noting the differences between the Korean ELLs and Japanese ELLs, especially for Move so (Table 3). The Japanese participants had a higher rate of frequency for many of the functions, albeit only by a little, but the difference in frequency between the two ELL groups for Move so was 1.2178. If a comparison were made between the EDS group and only the Japanese group, the difference in frequency would be 1.3768 , which is similar to the previous comparison, indicating the comparability between the Korean ELLs and the EDSs. However, this may not be conclusive because the comparison is between 10 EDSs and only five Korean participants. A larger and ideally equal sample size for all speaker groups would be necessary for a more reliable comparison of not only Move so, but of its other discursive functions as well.

\section{Topic-Marking So}

Marking the main topic is most salient in the first three discursive functions that are listed in Figure 1. Topic-marking so is essentially the same as marking the main topic (the underlying function), but has its own functional category as there are two subcategories that fall under Topic-marking: Main Topic and Return. These two subcategories have been derived from Brinton's (1996) definition of pragmatic markers: "[they] mark a boundary in discourse, that is, [they] indicate a new topic, a partial shift in topic (correction, elaboration, specification, expansion), or the resumption of an earlier topic (after an interruption)" (p. 37). Main Topic so introduces a brand new topic, thereby marking new topic "boundaries." It can also highlight pivotal moments, such as marking key points in the talk. Return so, on the other hand, brings the discourse back to the main topic after a departure from it.

\section{Main Topic}

So was often found to initiate discourse (Brinton, 1996) or introduce a new course of action (Bolden, 2009; Lam, 2010; Matzen, 2004). Participants marked the main topic using so by responding to the interview questions, by beginning a new topic on their own, or by introducing the main points in a narrative. In other words, the DM marked "the transition of a topic" (Fung \& Carter, 2007, p. 421), as demonstrated by the following three examples.

Excerpt 1 (EDS)

(1) Phil: ${ }^{6}$ all right (.) so ${ }^{7}$ it starts out with Mr. Bean trying to uh (..) get some=

(2) =stuff into his suitcase

Excerpt 2 (EDS)

(1) Lara: okay (.) so: a man is packing Mr. Bean is packing for his vacation=

(2) $=($.$) and he realizes that he has too much stuff in his suitcase$ 
Excerpt 3 (ELL)

(1) Int.: $\quad$ could you tell me what happened in that scene? (.) in as much= $=$ detail as you can

(3) Tatsuki: so he (.) tried to pack everything in a small (.) like a (.) garbage= $=$ no not garbage $($.$) like carry case =$

The transitions in Excerpts 1 and 2 were also marked by tokens of agreement, such as, "all right" and "okay," to acknowledge the shift from one speaker to the next, "project[ing] the discourse forward" (Fung \& Carter, 2007, p. 421) and preparing the hearer for the beginning of the story. Phil explicitly uttered the word, "start," in Excerpt 1 to further emphasize that he is introducing his story. The ELLs employed this function as well, but omitted the agreement tokens that preceded the EDSs' so, as demonstrated in Excerpt 3. In the same way that "macro connectors" denote the boundaries in a story, so marks the beginning of the participant's turn and the start of the narrative. The speaker also has the liberty to use so to distinguish and highlight the main points from the supporting ideas (Matzen, 2004), particularly in a narrative, where the speaker must convey a great deal of information. In the following flow of information (Excerpt 4) where Leo described the plot of a TV show, he used so (line [8]) to introduce the process of selling drugs, a crucial element to the story.

Excerpt 4 (EDS)

(1) Leo: and it's (.) it's a genius TV show because like it takes you=

(3) Int: $\quad$ okay

(4) Leo: $\quad=$ and you start off with the people that sell on the street (.) and= $=$ it's crack=

(6) Int.: $\quad$ yeah

(7) Leo: $\quad=$ and then you go on to the hitters like you know the people=

(9) Int.: $=$ that (.) so the way they sell is (.) you own a corner [and the guy=

(10) Leo: =that owns the corner has a boss who owns that site $()=$.

(11) Int.: yeah

(12) Leo: =and then this guy has another boss (.)...

Leo began by marking the main topic, stating that the show is about the drug business and the operation of this particular industry. In line (8), he simply introduced one of the components (main point) of the drug business, which is the actual selling of the products. The ELLs also employed so to distinguish key points in their speech, as demonstrated in Excerpt 5.

Excerpt 5 (ELL)

(1) Int: okay u:m what are other differences that you can think of?

(2) Kota: the food

(3) Int: food okay

(4) Kota: I I was I was worried about food [before I came here

(5) Int: [yeah 
(6) Kota: u:h so I like Japanese food and then I have some experience when I go to New York=

(8) Int: $\quad$ mhmm

(9) Kota: $\quad=$ for for a while for one week I didn't eat Japanese food=

(10) Int: $\quad$ o:h

(11) Kota: $\quad=$ for one week=

(12) Int: yeah

(13) Kota: =so that's why I I hate hamburger and some some meat=

A variety of topics were brought up while discussing the cultural differences between North America and Japan. Among them included food, and Kota highlighted the fact that he likes Japanese food by prefacing this main point with so in line (6), the significance of which is further emphasized by the event that is described in lines (6) to (13): going without Japanese food for a week was unbearable for him.

\section{Return}

After a short digression — “[presenting] a subtopic" (Matzen, 2004, p. 77)—or from a prolonged one that has been prompted "by some outstanding conversational agenda" (Bolden, 2009, p. 977), Return so is used to signal a return (Bolden 2009; Lam, 2010; Matzen, 2004; Müller, 2005) to the main topic of discourse. While the conditions of a semiformal, semistructured interview did not provide an opportunity for the resumption of a pending conversation that occurred prior to the interview (extended digression), so was used to return to pending talk that was put on hold during the interview (short digression). It was only used by the EDSs, often in storytelling, to return from a "parenthetical background segment" (Bolden, 2009, p. 981) and to refocus the attention back to "the common ground" (Clark, 1996, p. 346), as if there had never been an interruption. In Excerpt 6, Troy had just started explaining a TV show that he watches when I interrupted this action trajectory with a question about the length of an episode. In order to respond to this slightly off-topic question, the speaker digressed from the main topic before he returned in line (14).

Excerpt 6 (EDS)

(1) Troy: $\quad=u: m($.$) currently watching this anime [it's called Hunter \mathrm{x}=$

(2) Int.: [okay

(3) Troy: $\quad=$ Hunter u:m (.) it's about 148 episodes approximately=

(4) Int.: woah [how many minutes each?

(5) Troy: $\quad=$ [the prem=

(6) =how many minutes (.) it's about twenty [(.) minutes=

(7) Int.: [okay
[8) Troy:

(8) Troy: $\quad=$ I can't invest an hour into TV shows=

(9) Int.: [yeah

(10) Troy: $=$ [my life is just gonna go away if I watch that $=$

(11) Int.: =really?

(12) Troy: YEAH I've commitment issues when it comes to [TV shows

(13) Int.: [okay okay 
(14) Troy: so premise behind it [is that there's this boy (.) his name is Gon=

(15) Int.:

$$
=(.) \text { and }=
$$$$
[\text { okay }=
$$

(17) Troy:

$=$ he's (.) out on the mission to find his father (.)

The "premise" of the show was pending on the "interactional agenda" (Bolden, 2009), and Troy used so (line (14)) to mark his return to the main topic of the conversation. The main topic was interrupted before any information about the plot, besides the title and length of the show, was revealed. Hence, it is clear that Troy was making a return to the main topic when he stated that he will describe the premise. Moreover, there was no indication of any memory loss, confusion, or hesitations when the interrupted action trajectory was resumed (Bolden, 2009).

\section{Summary and Restatement/Rewording So}

Previous scholars have combined so's functions as a summary marker, restatement/rewording marker, and main topic marker, demonstrating Summary so's and Restatement/Rewording so's close affiliation with the main topic. Therefore, along with the connective function, marking the main topic is the most prominent underlying function for Summary and Restatement/Rewording so on the Spectrum (see Figure 1). Matzen (2004) categorized Summary so as a subcategory of Topic-marking so, while Müller (2005) combined marking summary, rewording, and giving an example into one functional category. Furthermore, as with Topic-marking so, both of the functions represented here are "resultative" only to the extent that their use results in either a summary or a restatement of the unit(s) that preceded it. In other words, the Resultative function is not as notable as the other two underlying functions.

Summary so and Restatement/Rewording so highlight or clarify a point made during the talk, insinuating that no new information follows so. While they both focus on prior utterance(s), only Summary so is associated with conclusions ${ }^{8}$ and acts on a global scale, as it takes "an idea originally expressed in more than one intonation unit" (Müller, 2005, p. 78 ) and condenses the idea into one single linguistic unit. Restatement/Rewording so, however, acts on a local level of discourse by paraphrasing a preceding utterance, usually for stress or clarification.

The following is an example of an EDS's production of Summary so.

Excerpt 7 (EDS)

(1) Liv: (.) um Mr. Bean had a small suitcase and he tried to get all of the=

(2) $=$ things that he wanted for presumably some sort of trip and $()=$.

(3) =made everything significantly smaller (.) or made decisions to $=$

(4) =try and cut things out or make them smaller even if it was=

(5) =wasteful (.) uh just to be able to fit it in the suitcase and then he=

(6) =realized he had a bigger suitcase (.) and gave up on everything=

(7) =and threw it all in the bigger suitcase

((some lines excluded))

(8) $\quad=$ so he takes (.) a real-life situation and is able to twist it into a=

(9) =way that makes it (.) comical 
After Liv recounted the Mr. Bean scene, she summarized her description and remarked on the character's actions in one linguistic unit using Summary so at the end of her talk in line (8). The information that came after the DM was already known to me, the hearer, and clarified a point that was made earlier in the talk. Even if I was unfamiliar with the character, I was now aware that Mr. Bean's actions were comical and that he was twisting a normal situation to amuse his audience, simply based on the information [lines (1) to (7)] that was provided by Liv. In other words, as the information that succeeded so is now already known to the hearer and has been explicitly delivered by the speaker, it is a summary.

Kyuri, in the following example, demonstrated a very similar use of Summary so.

Excerpt 8 (ELL)

(1) Int: all right so can you tell me what happened in the scene?

(2) Kyuri: u:h (.) so he just thinks thinks about the situation he (..) faced just right now?

(4) Int: $\quad$ mhmm

(5) Kyuri: so he doesn't think about the what will happen after they after he went

(7) Int: somewhere [he go somewhere

(8) Kyuri: $\quad$ yeah so and and so he's a little bit (..) not little bit he's stupid (hh)

(9) Int: $\quad$ (hh) yeah

(10) Kyuri: yeah so (..) and even if he got a he has he had a big suitcase

(11) Int: $\quad$ mhmm

(12) Kyuri: yeah (..) so mm he doesn't think about what he had (..) and he has

In line (2) Kyuri deduced that Mr. Bean does not think about the consequences of his actions and he only thinks about what is happening in the present. Mr. Bean had a bigger suitcase that would fit all of his belongings, but he only finds this suitcase at the very end of the scene. Therefore, Kyuri summarized all the points she had made from lines (2) to (10) and stated that "he doesn't think about what he [has]." Moreover, no new information followed so, and I was aware of Kyuri's conclusion in line (12), based on the information she had provided prior to the DM's production, indicating that so prefaced a summary.

In comparison, one ELL (at an average rate of 0.1486 per 100 words) and three EDSs (at an average rate of 0.0325 per 100 words) signaled a restatement with $s o$. Similarly, there was no significant difference between the two groups $(p=.468)$. In Excerpt 9 , I expressed confusion about what Liv meant by "red corral" in a conversation about the time we were both involved in a run.

Excerpt 9 (EDS)
(1) Liv:
I was in the like the red corral
(2) Int.:
I don't know what the red corral is
(3) Liv:
that's the first corral
(4) Int.:
oh [oh oh okay
(5) Liv:
[so I was in the first heat 
To ensure that I understood and/or to emphasize her position in the run, Liv paraphrased "red corral" twice. As I was unaware of the significance of the corral's colours, Liv explained that the red corral is the first corral in line (3). While I already expressed understanding in line (4), Liv rephrased once more in line (5). "First heat" was a repetition of "red corral" and "first corral," indicating that so prefaced a restatement/rewording.

Excerpt 10 illustrates the only ELL that employed this function.

Excerpt 10 (ELL)

(1) Int: well what what is that (.) what are they about? (.) what is that=

(2) =show about do you know?

(3) Kaho: $\quad \mathrm{u}: \mathrm{h}$ both animation mm in uh Anpanman and Doraemon helps someone

(4) Int: okay

(5) Kaho: so Doraemon always help Nobita to do something [and Anpanman help=

(6) Int:

(7) Kaho: $\quad=$ children or and battle with Baikinman $(\mathrm{hh})=$

$[\mathrm{mhmm}$

So in line (5) prefaced a restatement/rewording of the information that immediately preceded the DM. Moreover, based on the information in line (3), I was now somewhat familiar with Anpanman and Doraemon. So introduced the same information, but Kaho replaced "someone" with Nobita (the name of the protagonist on the show) and "children." Kaho had decided that it was important to specify that "someone" was a reference to Nobita in the Doraemon series and "children" in the Anpanman series.

\section{Reason/Result So}

To differentiate between its discursive and non-discursive functions, Schiffrin (1987) suggested that so can function on two different levels of discourse. On the local level, so ("so", n.d.) operates as a conjunction and can be defined as "[f]or that reason, on that account, accordingly, consequently, therefore" (n.p.). As a DM, so relates the main topic and functions on the global level by introducing the reason or outcome of several prior units. This outcome may signal the end of the talk, or it may propose a result or reason for an action (Matzen, 2004) in the middle of a narration. Some have also argued that the preceding statement directly results in the second proposition (Torres \& Potowski, 2008). Fraser (1996) classified so as an inferential marker, one of his subcategories of DMs, while Quirk, Greenbaum, Leech, \& Svartvik (1985) designated so as "resultive.” Despite Fraser's (1996) "[restriction of] the function of inferential DMs to marking conclusions" (Schourup, 1999), and Quirk et al.'s (1985) claim that his version of inferential markers (which include otherwise, in that case, and in other words) are the only markers to "indicate a conclusion based on 'logic and supposition' (1985: 638)" (Schourup, 1999, p. 260), there is evidence that $s o$, in fact, marks result or reason in some way. Nonetheless, all instances of

Reason/Result so in the present data signaled the consequence of prior utterances depicting continuity or illustrating a "temporal flow of story time" (Segal, Duchan, \& Scott, 1991, p. 46). Evidently, its underlying function was most prominently Connective and Resultative. There was still, however, a slight hue of marking the main topic, as the result or reason that so introduced was related to the topic of discourse (see Figure 1). 
In Excerpt 11, Linus describes the plot of his favorite book.

Excerpt 11 (EDS)

(1) Linus: =and it explains how (.) there's a viable planet with life perhaps=

(6) Int.:

(7) Linus: =need human candidates who are willing to leave everything= =somewhere and they want to explore it (.) but to get there and= $=$ the way time is distorted when you travel at really high speeds $=$ $=($.) they'll end up arriving hundreds of years into the future $()=$. $=[\mathbf{s o}$ they $=$ [okay

$=$ behind $($.

The outcome in line (7) was the consequence of the several units preceding the DM in line (5):

1. scientists have made an experiment for intergalactic traveling;

2. scientists have discovered a viable planet, perhaps with life;

3. scientists want to explore this potentially viable planet;

4. space-traveling means that time gets distorted; and

5. whoever space travels, will be arriving on this new planet hundreds of years into the future. (Lim, 2016)

In other words, all of the ideas from 1 to 5 contributed to the conclusion that the individual participating in this experiment must be willing to give up everything. Moreover, so in line (5) was discursive because removing it does not change the grammaticality of the utterance. Not having the DM simply means that the relationship between lines (1) to (4) and line (7) was not resultative. The connection was merely procedural, and it was because the DM was there that the hearer was able to make the inference that human participants were needed from the ideas that were presented before. Furthermore, unlike in Excerpt 7, where the information that succeeded the DM was already known, the information that came after so in Excerpt 11 was new. Linus did not mention the need for an individual who is "willing to leave everything behind" until after the DM, meaning that what came after so was the result of the "points" that preceded it, and not, say, a summary.

ELLs displayed a similar use of Reason/Result so, as demonstrated by Excerpt 12.

Excerpt 12 (ELL)

(1) Int.: yeah like what is the story about? (.) what is the show about?

(2) Taro: it's like a (.) not love story (.) it's kind of love story and everyone=

(7) Int.:

(8) Taro: $\quad=$ wonderful for $\mathrm{me}=$

(9) Int.: $\quad$ mhmm $=$ is trying to (.) so (.) trying to get girlfriend and (..) so (.) it was= $=$ so mixed so complex thing (.) and (..) so (.) there (.) and (.) the $=$ $=$ story was on the (.) another character comes out and (...) so it's= $=$ so $(\ldots)$ so: yeah fantastic $[$ and $=$

\section{$[\mathrm{mhmm}$}

The Canadian Journal of Applied Linguistics: 21, 1 (2018): 94-122 
(10) Taro: =and yeah I can I can engage in the story every time and (..) so $()=$.

(11) =yeah which is why I can finish that story (.) finally today

Taro's conclusion that he was able to finish the TV show was a consequence of the prior utterances as well. The story was complex, which made the show captivating for him, and he found the story "fantastic" and "wonderful." These points led to the ultimate conclusion: Taro was able to finish the TV series. Again, so is optional here and its removal from the utterance would not affect its grammaticality. Moreover, the discourse trajectory stayed on track throughout, and as a DM should, so connected the prior utterances with the utterance that followed the DM in line (11).

\section{Elliptical So}

This "pre-closing" (Schegloff \& Sacks, 1973) marker that signals an implied result (Müller, 2005) suggests a self-explanatory conclusion that is clear and coherent to the interlocutor because of the shared knowledge the speaker has with the hearer; this shared knowledge can come from the prior discourse sequence or from a talk that was put on hold in a former context (Schiffrin, 1987). Elliptical so, which has also been referred to as trailing (Torres \& Potowski, 2008) or stand-alone so (Raymond, 2004), relates the main topic and offers a conclusion all in one unit. It can occur in three different positions - turnfinally, turn-medially, and as a single unit - and oftentimes, the DM is also accompanied by a falling intonation (Buysse, 2014; Müller, 2005; Raymond, 2004), indicating that the speaker would like to close the talk (Buysse, 2014). Similar to Reason/Result so, Elliptical so most strongly indicates result and connects discourse (see Figure 1), as the DM offers a conclusion based on prior utterances (or actions) to end the speaker's turn.

When Elliptical so was used in the turn-final position, as in Excerpt 13 and Excerpt 14 , I took over the floor.

\section{Excerpt 13 (ELL)}

(1) Int: $\quad$ how much contact do you have with native speakers of English?

(2) Kaho: $\quad \mathrm{u}::$ h my roommate is native (.) speaker? (.) so:.

(3) Int.: oh okay (.) so everyday (.) okay

Kaho's use of so in line (2) implied that she has contact with native speakers of English on a regular basis because she lives with one. To avoid redundancy, she kept her response brief and allowed me to come to my own conclusion based on the information that was provided during this talk and what I already knew about this individual. Moreover, so was elongated and followed by a falling intonation, indicating that the speaker was trailing off [hence, Torres and Potowski's (2008) aptly named function, "trailing"] and that she wanted to conclude her turn.

In Excerpt 14, Leo described the Mr. Bean scene and made use of Elliptical so in the turn-final position.

Excerpt 14 (EDS)

(1) Leo: =and then uh (..) after that he grabs the teddy bear [and (.) he puts=

(2) Int.:

$[\mathrm{mhmm}$ 
(3) Leo: =it in the luggage and then he has a book (.) a [diary or something=

(4) Int.:

(5) Leo:

$=$ that he doesn't like (.) like pack in= $[\mathrm{mhmm}$

(6) Int.: mhmm

((some lines excluded))

(7) Leo: $\quad=$ and then (.) he's (.) going on vacation somewhere in England I=

(9) Int.: $=$ assume? I have no idea [or maybe Europe=

(10) Leo: =who knows but then he's on a train now so.

(11) Int.: great thank you all right (.)

So in line (10) implied that Mr. Bean could be going anywhere, based on Leo's utterance that $\mathrm{Mr}$. Bean is going somewhere for vacation. In other words, the significance of so encompassed (and connected) the prior utterance that Leo had no idea where Mr. Bean was headed. Here, the DM marked Leo's desire to turn over the floor to the interlocutor, and his request was successfully received when I took over the floor in line (11) with three different acknowledgements, "great," "thank you," and "all right." In the same way that the ELL's intonation fell after so in Excerpt 13, Leo's DM was also followed by a falling intonation, signaling his desire to end his turn.

Similarly, there were no notable differences between EDSs and ELLs for turnmedial so. Elliptical so occurs in turn-medial positions because so failed to close the turn. This can happen if the speaker decides to add some relevant afterthought (Buysse, 2014), or because the interlocutor fails to take the floor, as in the following examples, Excerpts 15 and 16.

Excerpt 15 (EDS)

(1) Int:: her accent was really thick? [you can't understand?

(2) Ella:

(4) Int.: $=$ like jetlagged and like [well it was just cause that it was $=$

(5) Ella: and we just got off (.) so.: u:m (.....) like (.) after that I didn't=

(6) =find it (.) hard to understand really?

(7) Int.: oh okay you just got used to it

Excerpt 16 (ELL)

(1) Int:: all right so can you tell me what happened in the scene?

(2) Kyuri: u::h (.) so he just thinks (.) thinks about (...) the situation= he (..)

(3) =he (..) u:h faced just right now?

(4) Int.: $\quad$ mhmm

(5) Kyuri: so he doesn't think about the (.) what (.) will happen after=

(6) =they (.) after he went somewhere [he go somewhere

(7) Int.: $[\mathrm{mhmm}$

(8) Kyuri: yeah so (.) and and (.) so he's a little bit (..) not little bit he's= =stupid (hh)

(10) Int.: (hh) yeah 
(11) Kyuri: yeah so. (..) and even if he got a he have he had a big suitcase

(12) Int: $\quad \mathrm{mhmm}$

In Excerpt 15, Ella talked about the time she went abroad and how she was unable to understand the salesperson because of her thick English accent. In line (5) it seems that Ella meant to end her turn at so because her jetlag explained her being unable to understand the salesperson's accent, the DM was produced with a falling intonation, and the pause that immediately preceded so prepared the hearer for a possible termination. Furthermore, what followed so was new information that was added because the interlocutor did not take over the floor when Ella had hoped she would. The interlocutor's failure may have also resulted in Ella using a hesitation marker to fill the pause. The fact that "um" was also elongated and that a long pause followed it may be an indication that she was simply attempting to fill the silence. Turn-medial positions are "potential [original emphasis] loci for shifting responsibility from speaker to hearer" (Schiffrin, 1987, p. 225), so when I failed to take over the floor after her production of so, Ella was forced to continue.

Similarly, so in line (11) of Excerpt 16 was produced with a falling intonation, unlike Kyuri's previous productions of so in the excerpt, which indicated a close. Kyuri intended to end her turn with the idea that Mr. Bean is "stupid," but as I did not take over the floor, she may have felt the need to continue. In addition, throughout the talk, I also offered frequent backchanneling, such as in line (7) with "mhmm" and in line (10) with synchronous laughter and "yeah." Kyuri may have picked up on my tendency to backchannel, whether it is verbally or non-verbally, and the absence of providing a backchannel or taking over the floor, may have led the speaker to continue holding the floor.

Elliptical so can also occur as a complete grammatical unit, hence the name, "standalone so" (Raymond, 2004). Raymond (2004) indicated that this function "invokes the continuing relevance of [a prior action]" (p. 210), and implies a conclusion or result all by itself. The intentional absence of a stated upshot after the DM is not seen as a failure. On the contrary, according to Raymond "its completion by the same speaker reflects a missed opportunity for collaboration and possibly even a failure" (p. 211). Furthermore, Raymond offered that the DM elicits the hearer to "solve what the so might be prompting [her or him] to acknowledge or do" (p. 211). Raymond suggested two types of stand-alone so. One indicates sequence expansion and the other sequence closure. With sequence expansion, the hearer reopens the talk that was meant to be closed because the speaker's first so failed to end the topic. After further expansion of the sequence, a second stand-alone so is employed by the same speaker to index closure. Only the latter type of Elliptical so manifested in the present study and exclusively in the EDS data. When participants used stand-alone so, it was always met with an expression that indicated understanding of the speaker's intention(s) of the one-word turn construction unit from me, an example of which is shown in Excerpt 17.

Excerpt 17 (EDS)
(1) Int.:
what's the Shomi service?
(2) Neil:
(3) Int.:
it's like Netflix but it's the [Rogers one
(4)
$[\mathrm{O}: \mathrm{H}$
is it online or on 
(5) Neil: no it's on the TV

(6) Int.: oh okay

(7) Neil: just on the on demand services=

(8) Int.: okay okay

(9) Neil: $\quad=$ so.

(10) Int.: oh cool

Neil produced the DM in line (9), anticipating some responsive action from me, which was indeed met with a short remark, acknowledging the closure. Whether or not the so is elongated, Schegloff and Sacks' (1973) description of its function remains relevant:

[Its purpose is] to indicate that [the speaker] has not now anything more or new to say, and also to give a "free" turn to a next, who, because such an utterance can be treated as having broken with any prior topic, can without violating topical coherence take the occasion to introduce a new topic, e.g., some heretofore unmentioned mentionable. AFTER such a possible pre-closing is specifically a place for new topic beginnings. (p. 304)

\section{Move So}

Unlike so's other discursive functions, Move so does not relate the main topic nor does it indicate a reason or result (see Figure 1). However, it has a connecting function and can occur in a variety of positions. Its function is comparable to that of a "filler" (Bortfeld, Leon, Bloom, Schober, \& Brennan, 2001; Clark \& Fox Tree, 2002; Corley \& Stewart, 2008; Gilquin, 2008) or a "filled pause" (Goldman-Eisler, 1961; Kjellmer, 2003). Some have described it as a "hesitation disfluency" (Bortfeld et al., 2001; Corley \& Stewart, 2008), such as $u h$ and $u m$, as they indicate uncertainty about what to say next (Corley \& Stewart, 2008), hesitation (Bortfeld et al., 2001; Corley \& Stewart, 2008), and disruption in the fluency of speech (Tottie, 2011). While some have suggested that fillers are produced unintentionally (Corley \& Stewart, 2008), others have argued that "speakers plan for, formulate, and produce [fillers] just as they would any word" (Clark \& Fox Tree, 2002, p. 73), including DMs such as so. Moreover, fillers indicate planning (Tottie, 2011) and planning problems (Clark \& Fox Tree, 2002), which may also be applicable to Move so. In particular, Move so was used by participants in this study to indicate a progression in the narrative that "[did] not imply consequence, result, or conclusion" (Torres \& Potowski, 2008 , p. 269). While there was progression or motion, there was no meaningful development in the story or talk.

Let us compare an EDS example (Excerpt 18) with an ELL example (Excerpt 19).

Excerpt 18 (EDS)

(1) Int.: okay and could you pick a character from this show and describe=

(3) Ella: okay u:m

(4) Int: $\quad$ one that you like or don't like

(5) Ella: okay u::h so: (...) let's say Buster 
Excerpt 19 (ELL)

(1) Nori: I think (...) like (..) like (.) this is I think common comedy in=

(2) =American but I think (.) u:h no like talking we (.) we enjoy=

(3) =talking [with each other so and comedians=

(4) Int.: [okay

(5) Nori: $\quad=$ will so pick up the so personality like so funny talk or=

(6) =like so many so but the (.) like (.) Mr. Bean will so attend the=

(7) $\quad=$ like so funny action so

Move so's similarity to a filler is most evident in the EDS examples, such as the one displayed in Excerpt 18. So in line (5) is further reinforced as a Move so by the elongated "uh" that preceded it, preparing the hearer for a pseudo-filled pause (Move so), which was then followed by an actual pause. So was not produced with a falling intonation, which implies that it is not an Elliptical so. In other words, the hearer was not expecting Ella to end her turn at so. All of these tiny productions (or lack thereof) could indicate the speaker's desire to hold the floor, and her use of Move so indexed a potential effort to avoid overusing fillers such as $u h$ or $u m$, which could be more distracting.

Excerpt 19 was taken from the participant who employed Move so with the highest rate of frequency (at an average rate of 3.4483 per 100 words). Nori employed Move so especially when he had to hold a longer turn. In one turn, Move so occurred eight times, and each time it did not signal coherence or "deliver any relevant information to the previous" (Ko, 2013, p. 39) or succeeding utterances surrounding the DM as so does in its other functions. Although so in "so pick up" or "like so many" could function as an adverb to mean will definitely pick up and numerous, respectively, they are considered to be instances of Move so because there were no pauses or lengthening of vowels to indicate a non-discursive function. Move so is not to be confused with indicating the main topic or continuing the story. Its frequent repetition is a disruption to the flow of speech $(\mathrm{Ko}, 2013)$, and rather than guiding the hearer, it can be inferred as a distraction that merely pushes the utterance forward without advancing the plot or story. So was also often found to be preceded or followed by like, and, or but. The DM occurred multiple times throughout this excerpt, which can be seen as a "filler or delaying tactic . . . to sustain [the] discourse or hold the floor" (Brinton, 1996, p. 37). Nori may not have had pauses surrounding the DM or elongated the DM, but this repetition of so functioned similarly to when so occurs with pauses and/or fillers in order to hold his turn and/or "as a delay tactic for planning and time-stalling" (Lam, 2010, p. 669). These instances of so can be seen as replacing what would have been a pause or filler without affecting the proposition of the utterance (Ko, 2013). Excerpts 18 and 19 were examples from the present study where participants employed so "without any specified meaning in the context" (Ko, 2013, p. 37), but sought to connect discourse.

\section{Comparison to Others' Findings}

Similar to Asik and Cephe's (2013) study, where the learners were limited in function compared to the EDSs, the learners in the present study were also found to be less flexible with their use of so's functions. While it is probable that the current investigation's small sample size blurred any significant differences between the ELLs and EDSs, the 
ELLs' limited range of functions shows that they will not be able to make use of DMs such as so to their full potential. The ELLs in Fung and Carter's (2007) study demonstrated that even the more common DMs that were used by the British EDSs, such as well and right, were found to be limited in their speech. Buysse's (2012) finding that some functions, such as "elaborative so" and "self-corrective so," were more prevalent in the ELLs' speech could be justified by the fact that ELLs "use vaguer terms that require elaboration than their native peers" (p. 1778). A restricted range of functions does not seem to be exclusive to learners of English. Rehner (2002) concluded that French learners' use of the discursive functions of alors (roughly the equivalent of so in English) was much more limited than the native speakers' use of the DM. It is, therefore, also probable that the same opportunities did not arise for each participant to demonstrate their potential ability and knowledge of a function, which could have influenced the results of the present study that indicated that the range of functions was narrower for ELLs than EDSs.

Past studies have generally concluded that there is a discrepancy between ELLs' and EDSs' use of DMs. The present study yields a similar conclusion for the six discursive functions of $s o$, particularly Move so, presented in this paper (see Table 4). If Ko's (2013) Korean participants' frequencies of DM so (290 instances) and discourse filler so (221 instances) were combined and the native speakers' DM so (277 instances) and discourse filler so (106) were combined, the Korean participants had a higher frequency of 157 instances. Frequencies for both tokens must be combined in order to compare my data to Ko's, as I refer to Move so as a DM and not a discourse filler. Considering the 12,389 words (about $3.96 \%$ of the learners' total word count) in the learner data and the 34,358 words (about $0.97 \%$ of the native speaker's total word count) in the native speaker data, the Korean participants had a higher frequency of more than four times. Buysse (2012) also concluded that $s o$ was more frequently used by the learners than the native speakers in that study, with a statistically significant difference.

The outcome of the present study could be attributable to multiple factors. First of all, the sample size of the study was likely too small for any differences to be significant. There were two different L1 groups, Korean and Japanese, with only five participants each. If the conclusion were influenced by participants' L1s, the low number of participants in each L1 group may have produced an inaccurate representation of the ELL group. However, as Ko (2013) also only had 11 preservice Korean English teachers, it is unclear if results from either study could be generalizable. Buysse (2012), however, analyzed a learner corpus consisting of 40 Flemish ELLs and obtained similar results to Ko. In addition to more studies exploring the use of DMs such as $s o$, a greater number of participants from each speaker group are necessary for a better reflection of the use of DM so by EDSs and ELLs. It seems that the investigation of DMs, in general, has yielded varying results. The ELLs in Iglesias Moreno's (2001) study did not make much use of discursive well and when they did, the uses were often deemed "inappropriate." $\mathrm{Bu}$ (2013) also discovered that only one out of the 30 ELLs in that study used the DM and only twice. On the contrary, Müller (2004) found that ELLs had a higher frequency rate for well than EDSs. She examined the DM on three different levels - local, structural, and dialog 9 - and concluded that the differences were statistically significant for some of the functions. The discrepancy, however, could be attributed to factors such as the context of the interactions (Fuller, 2003) and the participants' L1s. 


\section{Discussion}

Topic-marking so was the only function used by every EDS and was the most frequently used function by this speaker group (at an average rate of 0.5394 per 100 words). While both groups employed so to mark the main topic or preface the main points in a narrative, the ELLs did not employ agreement tokens with their Topic-marking so's. The ELLs also did not introduce a subtopic, suggesting that they may be unaware of this function and that transitioning from one topic to another could seem brusque. While it is possible that the context of an interview, where turn-taking may be more frequent, may not have yielded an opportunity to introduce a digression, the fact that some EDSs were able to employ this function highlights the disparity between ELLs and EDSs. Both Restatement/Rewording so and Summary so were similarly used by ELLs, as there was only one instance for each function. The first of the two functions was employed at an average rate of 0.0149 per 100 words by the ELLs and at a rate of 0.0325 per 100 words by the EDSs. In addition to the greater word count the EDSs had, there were only four participants (one ELL and three EDSs) who used this function at very low rates, which evidently resulted in similar rates of use. This function helps to clarify a preceding statement, and when it is not used when it could be, the conversation may become unclear and/or disorganized later on. While it was not employed by most of the EDSs either, ELLs should still be aware of its significance in talk and its usefulness in indicating an upcoming paraphrase. Summary so yielded very similar results. The similarities in use by the EDSs and ELLs demonstrates that the ELLs in this study are not incapable of employing so to mark the main topic and connect discourse (the two major underlying functions of Topicmarking, Restatement/Rewording, and Summary so).

Although there was no significant difference between the EDSs and ELLs for Reason/Result so, the EDSs had a higher rate of use by 0.1657 per 100 words, which is the greatest difference between the groups after Move so. Elliptical so was produced by the EDSs at an average rate of 0.1908 per 100 words, compared to the ELL group that produced the DM at a rate of 0.0833 per 100 words. While averaging the rate of use could obscure the outliers or individual idiosyncrasies, such as one EDS's habit of frequently producing Elliptical so's, it also means that researchers may fail to consider learners' idiosyncrasies, which likely do exist. Nonetheless, no ELL made use of stand-alone so, which could illustrate that the learners may have not yet acquired the ability to form a oneword turn construction unit. Stand-alone so is available for speakers to facilitate talk (Raymond, 2004), and ELLs should learn to employ it when they can. However, the lack of notable discrepancies between the speaker groups' turn-final so suggests that the ELLs are just as capable as the EDSs in marking the closure of a discourse topic (Schiffrin, 1987) or a turn (Matzen, 2004; Torres \& Potowski, 2008). Therefore, Reason/Result so and Elliptical so's resultative and connective nature may be understood to some extent by the ELLs, but it is not yet certain as to just how much.

The final function on the Spectrum (see Figure 1), Move so, was the most frequently used function by ELLs (at an average rate of 0.7844 per 100 words), but one of the least frequently used functions by the EDSs (at an average rate of 0.0165 per 100 words). While the high frequency rate for this function is attributable to two Japanese ELLs, it was used by the majority of the group (eight ELLs). Nonetheless, the fact that Taro's and Nori's rates of use (3.1145 and 3.4483 per 100 words, respectively) exceeded all 
of the other participants' rates (see Table 4$)$, and the average of all participants $(0.4005$ per 100 words) by about eight times, could indicate their struggle with pragmatic competence. Moreover, this unusually high rate of frequency for Move so could indicate that the ELLs actually do not quite understand how to use DM so. The fact that many of their productions of the DM fall under this category, more so than others, could imply that their "successful" uses of its other discursive functions may have been a coincidence. Nevertheless, Shimada (2014) also concluded that Japanese ELLs had a much higher rate of frequency than other ELL groups for the use of Move so. ${ }^{10}$ It would therefore be beneficial to exhaustively explore L1 influence and cultural influence. It is also worth noting Tanaka's (2010) study of Japanese DMs such as ee. Although ee does not translate to so in English, ee's function as a DM is potentially comparable to that of Move so. Ee's purpose of showing attention and interest (Tanaka, 2010) may be one of the reasons Japanese ELLs frequently produced Move so in the present study. In an attempt to make up for slower word-searching and word-production times, or to signal that they are not yet ready to give up the floor, Japanese ELLs may have employed Move so at a higher rate than the Korean ELLs and the EDSs. Hence, to obtain a more accurate representation of ELLs' use of Move so, larger ELL groups are necessary. A larger study examining both the L1 and L2 would help determine whether the use of Move so is in any way related to the Japanese language or a speaker's L1.

Rehner (2002) had similar results for the French DM comme (roughly the equivalent of like in English), where the DM was much more frequent in the learner data. Furthermore, Aaron (2004) and Torres and Potowski (2008) discovered that so and the Spanish equivalent, entonces, was used comparably by bilingual Spanish and English speakers. In Flores-Ferrán's (2014) study DMs were presented in "single, double, triple, or more" (p. 66) combinations, where the DM or DMs were only produced in English, only in Spanish, or in both languages. It seems that when a speaker has difficulty organizing talk in the L2 and/or has many languages at his or her disposal, the speaker may turn to employing a "move" DM, such as Move so or an L1 equivalent. Instead of signaling struggle with other L2 DMs or in other ways, speakers choose the DM that is "effective with respect to communication" (Flores-Ferrán, 2014, p. 79). The ELLs' purpose of Move so, then, may have been an attempt to produce an effective utterance when they did not know any better way to do so. In addition, Aaron's (2004) study not only suggested that so triggers codeswitches in certain environments, but so was also found in monolingual Spanish. While so does not occur in monolingual Korean or Japanese, the fact that so is a DM that is produced with codeswitches (i.e., with a language other than English), could underscore a unique function it plays in the interlanguage of ELLs. This further supports the need to simultaneously explore L1 equivalent DMs to better comprehend ELLs' use of English DMs, such as so.

\section{Conclusion and Future Directions}

This study has demonstrated that ELLs are capable of employing discursive so, but to a much lesser extent than their EDS counterparts. Their frequent use of Move so in particular, whose main underlying function is connective, demonstrates that ELLs are at least aware or have gained an understanding of DMs' fundamental nature to connect discourse. While it is not absolutely certain whether or not they have developed an 
understanding of so's underlying function to mark the main topic and result, their ability to employ Topic-marking so indicates their familiarity with marking the topic using a DM. Moreover, the overall difference in rate of use was not as great as I had initially hypothesized.

In comparison, ELLs had a lower rate of frequency and a more limited range of functions. Even though most differences were subtle, they can still impede one's speech and the speaker may appear less pragmatically competent. The repetition of Move so, for example, may distract the hearer instead of guiding the hearer, contradicting the purpose of a DM. Moreover, the absence of so to introduce a digression in the learner group could mean that the hearer may not be prepared to transition from one topic to another and the thus the transition may seem abrupt. Further exploration of DM use in speakers' L1 and L2 is necessary to determine if positive and negative transfers from the L1 to the L2 are a result of being a language learner or numerous other factors. The frequency of Move so was particularly notable, and their lack of understanding of so's role in speech, negative L1 transfers, among many other possible factors, seem to have resulted in ELLs' differing uses of so compared to EDSs.

Being a smallscale study meant that the results might not be generalizable and that quantitative analysis would be limited. Furthermore, more participants would have allowed an analysis of variance. However, the major limitation in this study arose during qualitative analysis of the ELL data. While ELLs enrolled in the more advanced levels of their English program were sought, this did not guarantee high proficiency levels, making it difficult to comprehend their talk and complicating the analysis of so's functions at times. To compensate for this dilemma, the content of the talk was closely observed when instances of $s o$ were categorized.

Future research should include a longitudinal investigation into the relationship between the long-term effects of EDS contact and DM use and, correspondingly, pragmatic competence. An exploration of the effects of implicit and explicit instruction of DMs, accompanied by L2 exposure, could highlight the need for the formal instruction of DMs in the classroom. In past studies, formal instruction and sufficient L2 exposure have been found to be essential in assisting language learners to achieve pragmatic competence (e.g. Katayama, 2012; Pellet, 2005; Rehner, 2002). Moreover, a larger study examining other DMs and their respective equivalents in the speakers' L1s would yield a more thorough analysis of the L1's role in foreign language acquisition.

Correspondence should be addressed to Jessica Lim.

Email: jessicaj.lim@utoronto.ca 


\section{Notes}

${ }^{1}$ Using an "other-attentive" marker requires the speaker to have some kind of knowledge about the interlocutor, for "communication is not purely informational but a medium for social action" (Bolden, 2006, p. 681).

${ }^{2}$ See Buysse (2014) for a detailed explanation of non-prefatory so.

${ }^{3}$ This paper has been adapted from the author's Master's thesis project (Lim, 2016).

${ }^{4}$ Müller (2004) conducted a similar task using a Charlie Chaplin film.

${ }^{5}$ Müller (2004) also recoded her own data 2 weeks later for coding reliability.

${ }^{6}$ All names are pseudonyms.

${ }^{7}$ Instances of so that represent the function under analysis in the excerpt are bolded.

${ }^{8}$ While marking summary (Buysse, 2012) can also be the conclusion of a series of events, a conclusion does not necessarily represent a summary.

${ }^{9}$ See Müller (2004, p. 1164) for a description of the three levels.

${ }^{10}$ Shimada (2014) refered to this function as a "filler" in his study.

\section{References}

Aaron, J. E. (2004). "So respetamos un tradición del uno al otro": So and entonces in New Mexican bilingual discourse. Spanish in Context, 1(2), 161-179.

Aijmer, K. (2011). Well I'm not sure I think... The use of well by non-native speakers. International Journal of Corpus Linguistics, 16(2), 231-254.

Asik, A., \& Cephe, P. T. (2013). Discourse markers and spoken English: Nonnative use in the Turkish EFL setting. English Language Teaching, 6(12), 144-155.

Blakemore, D. (1987). Semantic constraints on relevance. Oxford, United Kingdom: Blackwell.

Blakemore, D. (1988). So as a constraint on relevance. In R. Kempson (Ed.), Mental representation: The interface between language and reality (pp. 183-195). Cambridge, United Kingdom: Cambridge University Press.

Bolden, G. B. (2006). Little words that matter: Discourse markers "so" and "oh" and the doing of other-attentiveness in social interaction. Journal of Communication, 56, 661-688.

Bolden, G. B. (2009). Implementing incipient actions: The discourse marker 'so' in English conversation. Journal of Pragmatics, 41, 974-998.

Bortfeld, H., Leon, S. D., Bloom, J. E., Schober, M. F., \& Brennan, S. E. (2001). Disfluency rates in conversation effects of age, relationship, topic, role, and gender. Language and Speech, 44(2), 123-147. 
Brinton, L. J. (1996). Pragmatic markers in English: Grammaticalization and discourse functions. Berlin, Germany: Mouton de Gruyter.

$\mathrm{Bu}$, J. (2013). A study of the acquisition of discourse markers by Chinese learners of English. International Journal of English Studies, 13(1), 29-50.

Buysse, L. (2012). So as a multifunctional discourse marker in native and learner speech. Journal of Pragmatics, 44, 1764-1782.

Buysse, L. (2014). "So what's a year in a lifetime so." Non-prefatory use of so in native and learner English. Text \& Talk, 34(1), 23-47.

Clark, H. H. (1996). Using language. Cambridge, United Kingdom: Cambridge University Press.

Clark, H. H., \& Fox Tree, J. E. (2002). Using $u h$ and $u m$ in spontaneous speaking. Cognition, 84, 73-111.

Corley, M., \& Stewart, O. W. (2008). Hesitation disfluencies in spontaneous speech: The meaning of um. Language and Linguistics Compass, 2(4), 589-602.

Flores-Ferrán, N. (2014). So pues entonces: An examination of bilingual discourse markers in Spanish oral narratives of personal experience of New York City-born Puerto Ricans. Sociolinguistic Studies, 8(1), 57-83.

Fox Tree, J. E. (2010). Discourse markers across speakers and settings. Language and Linguistics Compass, 4(5), 269-281.

Fraser, B. (1990). An approach to discourse markers. Journal of Pragmatics, 14, 383-395. Fraser, B. (1996). Pragmatic markers. Pragmatics, 6(2), 167-190.

Fraser, B. (1999). What are discourse markers? Journal of Pragmatics, 31, 931-952.

Fuller, J. M. (2003). Discourse marker use across speech contexts: A comparison of native and non-native speaker performance. Multilingua, 22, 185-208.

Fung, L., \& Carter, R. (2007). Discourse markers and spoken English: Native and learner use in pedagogic settings. Applied Linguistics, 28(3), 410-439.

Gilquin, G. (2008). Hesitation markers among EFL learners: Pragmatic deficiency or difference? In J. Romero-Trillo (Ed.), Pragmatics and corpus linguistics: A mutualistic entente (pp. 119-149). Berlin, Germany: Mouton de Gruyter.

Goldman-Eisler, F. (1961). A comparative study of two hesitation phenomena. Language and Speech, 4(1), 18-26.

Hellermann, J., \& Vergun, A. (2007). Language which is not taught: The discourse marker use of beginning adult learners of English. Journal of Pragmatics, 39, 157-179.

Iglesias Moreno, A. E. (2001). Native speaker-non-native speaker interaction: The use of discourse markers. ELIA, 2, 129-142.

Katayama, A. (2012). Effects of instruction on Japanese discourse marker $n$ desu (Master's thesis). Retrieved from ProQuest.

Kjellmer, G. (2003). Hesitation. In defence of er and erm. English Studies, 84(2), 170-198.

Ko, H. S. (2013). Overuse of the discourse filler, "so" in micro-teaching talks by Koreans. Language Research, 49(1), 25-44.

Lam, P. W. Y. (2010). Toward a functional framework for discourse particles: A comparison of well and so. Text \& Talk, 30(6), 657-677.

Lenk, U. (1998). Marking discourse coherence: Functions of discourse markers in spoken English. Tübingen, Germany: Narr.

Liao, S. (2008). Variation in the use of discourse markers by Chinese teaching assistants in the US. Journal of Pragmatics, 41, 1-16. 
Lim, J. J. (2016). Discourse marker so: A comparison between English language learners and English-dominant speakers (Master's thesis). Retrieved from ProQuest.

Local, J., \& Walker, G. (2005). Methodological imperatives for investigating the phonetic organization and phonological structures of spontaneous speech. Phonetica, 62, $1-12$.

Matzen, L. (2004). Discourse markers and prosody: A case study of so. LACUS Forum XXX: Language, Thought and Reality, 30, 75-94.

Müller, S. (2004). 'Well you know that type of person': Functions of well in the speech of American and German students. Journal of Pragmatics, 36, 1157-1182.

Müller, S. (2005). Discourse markers in native and non-native English discourse. Amsterdam, Netherlands: John Benjamins.

Pellet, S. H. (2005). The development of competence in French interlanguage pragmatics: The case of the discourse marker 'donc' (Doctoral dissertation). Retrieved from ProQuest (3217159)

Quirk, R., Greenbaum, S., Leech, G., \& Svartvik, J. (1985). A comprehensive grammar of the English language. London, United Kingdom: Longman.

Raymond, G. (2004). Prompting action: The stand-alone "so" in ordinary conversation. Research on Language and Social Interaction, 37(2), 185-218.

Rehner, K. (2002). The development of aspects of linguistic and discourse competence by advanced second language learners of French (Doctoral dissertation). Retrieved from ProQuest

Schegloff, E. A., \& Sacks, H. (1973). Opening up closings. Semiotica, 8(4), 289-327.

Schiffrin, D. (1987). Discourse markers. Cambridge, United Kingdom: Cambridge University Press.

Schourup, L. (1999). Discourse markers. Lingua, 107, 227-265.

Segal, E. M., Duchan, J. F., \& Scott, P. J. (1991). The role of interclausal connectives in narrative structuring: Evidence from adults' interpretations of simple stories. Discourse Processes, 14, 27-54.

Shimada, K. (2014). Contrastive interlanguage analysis of discourse markers used by nonnative and native English speakers. JALT Journal, 36(1), 47-68.

So. (n.d.). In Oxford English Dictionary. Retrieved from http://www.oed.com.myaccess.library.utoronto.ca/view/Entry/183635?rskey=rcQ fb2\&result=2\#eid

Tanaka, L. (2010). Is formality relevant? Japanese tokens hai, ee and un. Pragmatics, 20(2), 191-211.

Torres, L., \& Potowski, K. (2008). A comparative study of bilingual discourse markers in Chicago Mexican, Puerto Rican, and MexiRican Spanish. International Journal of Bilingualism, 12(4), 263-279.

Tottie, G. (2011). Uh and um as sociolinguistic markers in British English. International Journal of Corpus Linguistics, 16(2), 173-197.

Van Dijk, T. A. (1979). Pragmatic connectives. Journal of Pragmatics, 3, 447-456.

Zarei, F. (2012). An investigation of discourse markers in English. The Journal of Linguistic and Intercultural Education, 5, 191-220. 


\section{Appendix}

\section{Symbols Used in Transcriptions}

\begin{tabular}{ll}
\hline Symbol & Definition \\
\hline[ & $\begin{array}{l}\text { Overlapping speech } \\
\text { Continuation of an utterance (The turn continues where the next } \\
\text { symbol is inserted. If it is inserted at the beginning of the } \\
\text { second speaker's turn immediately following the first } \\
\text { speaker's turn, it indicates that there is no break between the } \\
\text { two speakers' turns.) }\end{array}$ \\
& $\begin{array}{l}\text { Every half a second pause } \\
\text { Rising intonation (not necessarily a question) }\end{array}$ \\
(.) & $\begin{array}{l}\text { Falling intonation } \\
\text { Increased volume }\end{array}$ \\
Capital letters & Laughter \\
$($ (unintelligible)) & Incomprehensible talk \\
$(\quad)$ & Unclear talk \\
$\ldots$ & Suspension of talk (due to time constraints) \\
\hline
\end{tabular}

